\title{
Effect of Red Mud Particles on Scratch Resistance of Aluminum Based Metal Matrix Composites
}

\author{
Lokesh K. S. *, Bandu Ummaji, Gururaj P., K. Rayappa, Yashavantha J. \\ Mechanical Department, Srinivas Institute of Technology, Mangaluru, India \\ Email address: \\ lbharani79@gmail.com (Lokesh K. S.) \\ ${ }^{*}$ Corresponding author \\ To cite this article: \\ Lokesh K. S., Bandu Ummaji, Gururaj P., K. Rayappa, Yashavantha J. Effect of Red Mud Particles on Scratch Resistance of Aluminum \\ Based Metal Matrix Composites. American Journal of Aerospace Engineering. Vol. 5, No. 1, 2018, pp. 24-29. \\ doi: 10.11648/j.ajae.20180501.14
}

Received: January 19, 2018; Accepted: February 3, 2018; Published: February 28, 2018

\begin{abstract}
Light weight structures reflect the most predictable aspects which are correlated with commercial usage in various applications where enhancing strength with lesser weight makes them measurable. Metals like aluminum with variety of grades acts as matrix to access the minute particles exhibits huge benefits once made by most convenient techniques to term them as metal matrix conjugates. Red mud emerges as the major waste material during production of alumina from bauxite by the Bayer's process. It comprises of oxides of iron, titanium, aluminium and silica long with some other minor constituents. Based on economics as well as environmental related issues, enormous efforts have been directed worldwide towards red mud management issues i.e. of utilization, storage and disposal. Different avenues of red mud utilization are more or less known but none of them have so far proved to be economically viable. Hardness property is improved remarkably by introducing hard intermetallic compound into the aluminium matrix. Thereinforcing materials are generally contain Silicon carbide, alumina as constituents which are costly to inculcate as a major part so that introducing this composition in aluminium matrix leads to property enhancement for the prepared metal matrix composites. Keeping this aspect in mind the present research aim is to explore the use of red mud as a reinforcing material which contains the above said composition as well as low cost option when used with aluminium. Samples are prepared by stir casting technique. Castings are cut, turned and shaped into the required size to prepare the specimens for evaluation of hardness number of samples. It is observed that the inclusion of the red mud is drastically affecting the hardness factor of the composites. The increase of the red mud composite weight percentage has decreased the hardness indicating the formability of the material.
\end{abstract}

Keywords: Red-mud Composites, $\mathrm{Al}_{2} \mathrm{O}_{3} / \mathrm{Al}$ Light Weight Structures, Advanced MMC's

\section{Introduction}

Aluminium alloys are preferred engineering material for automobile, aerospace and mineral processing industries for various high performing components that are being used for varieties of applications; owing to their lower weight and excellent thermal conductivity properties. Among several series of aluminium alloys, heat treatable Al6061 and Al7075 are much explored, among them Al6061 alloy are highly corrosion resistant, exhibits moderate strength and finds much applications in the fields of construction, automotive and marine applications. Due to their high strength, fracture toughness, wear resistance and stiffness, these metals stand high in interest. Further these composites are of superior in nature for elevated temperature application when reinforced with ceramic particle. Metal matrix composite materials have found application in many areas of daily life often which is not realized that the application make use of composite materials. These materials are produced in situ from the conventional production and processing of metals [1]. Process parameters plays a vital role on properties of Al based MMC. There are several processes are there for production of metal matrix composites, stir casting is one of the most convenient 
method where process parameters are regulated with most effective way. In case of Stir casting, process parameters like stirring rate, stirring temperature, pouring temperature to be maintained for achieving better properties of MMC's [2]. Tribological studies and other mechanical properties evaluation of the above produced MMCs can also be investigated [3]. Waste material like fly powder and rice husk fiery remains are use in 5 to $15 \%$ then acquire the composite material which have great wear, erosion and warmth protection properties[4].Addition to this use of graphene powder is used as a reinforced material in aluminum matrix is observed to enhance hardenabilty of aluminum. It is noticed that Graphene particles improves hardenabilty of soft matrix bearing more load and records 78RHN as compared to the parental composition[5] Aluminium matrix is getting strengthened when it is reinforced with the hard ceramic particles like Silicon carbide, Aluminium oxide and Boron carbide etc[6]. This present work highlights Develop a standardized process of stir casting process to synthesize red mud composites by utilising Al6061 with red mud particles as reinforcement and Study experimentally the hardness number of Al6061red mud composites by added with different percentage by weight proportion.

\section{Materials \& Methodology}

Bellow discussion highlights the empirical view of effective utilization of constituent materials and devices for the successful finishing of red mud based aluminum based metal matrix composites.

\subsection{Red Mud as Reinforcement}

Red mud emerges as the major waste material during production of alumina from bauxite by the Bayer's process. It comprises of oxides of iron, titanium, aluminium and silica along with some other minor constituents. Based on economics as well as environmental related issues, enormous efforts have been directed worldwide towards red mud management issues i.e. of utilization, storage and disposal. Different avenues of red mud utilization are more or less known but none of them have so far proved to be economically viable or commercially stable.In India, about 4.71 million produced which is $6.25 \%$ of world's total generation. It is the insoluble product after bauxite digestion with sodium hydroxide at elevated temperature and pressure. It is a mixture of compounds originally present in the parent mineral bauxite and of compounds formed or introduced during the Bayer cycle. It is disposed as slurry having a solid concentration in the range of $10-30 \%, \mathrm{pH}$ in the range of 10-13 and high ionic strength.

Table 1. Chemical constituent of red mud.

\begin{tabular}{lllllll}
\hline Chemicalconstituent & $\mathrm{Fe}_{2} \mathbf{O}_{3}$ & $\mathbf{A l}_{2} \mathbf{O}_{3}$ & $\mathbf{S i O}_{2}$ & $\mathbf{C a O}$ & $\mathbf{N a}_{2} \mathbf{O}$ & $\mathbf{T i O}_{2}$ \\
\hline Percentage & $30-60 \%$ & $10-20 \%$ & $3-50 \%$ & $2-8 \%$ & $2-10 \%$ & $25 \%$ \\
\hline
\end{tabular}

Table 2. Physical Properties of red mud.

\begin{tabular}{ll}
\hline Properties & Values \\
\hline Maximum dry Density $(\mathrm{g} / \mathrm{cc})$ & 1.53 \\
Optimum moisture Content $(\%)$ & 31 \\
Specific Gravity & 2.85 \\
Liquid Limit $(\%)$ & 40 \\
Cohesion $\left(\mathrm{kg} / \mathrm{cm}^{2}\right)$ & 0.125 \\
Angle of internal friction(In Degree's) & 26 \\
\hline
\end{tabular}

Raw red mud which is collected before and after sieving is as shown in figure 1

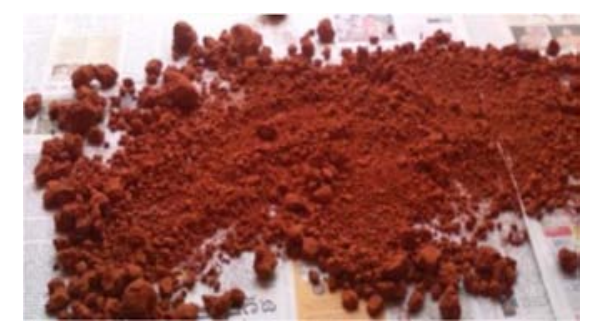

(a) Before sieve

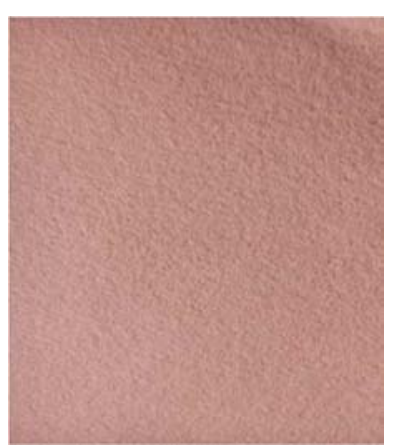

(b) After sieve

Figure 1. Red mud.

Figure 2 shows red mud particles of size 150 microns are obtained with the help of sieves.

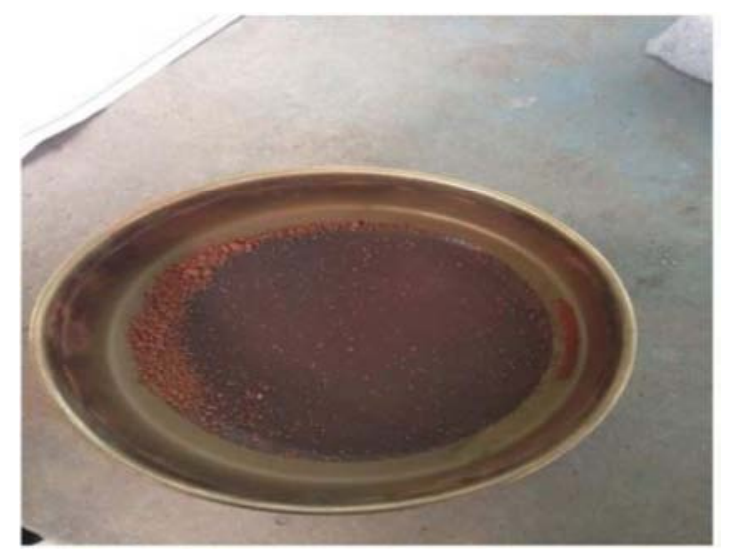

Figure 2. 150 microns sieve.

\subsection{Matrix Material}

For the present investigation aluminum 6061 which is as shown in figure 3 was used as a matrix material which is heat treatable and extrudable alloy which is widely used in commercially and chemical composition and major 
properties of aluminum 6061 are shown in table $3 \& 4$ respectively

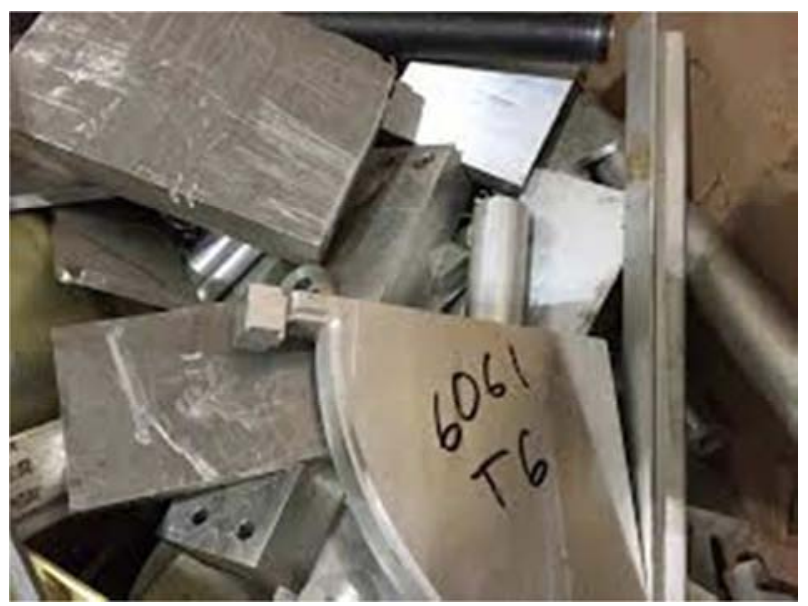

Figure 3. Commercial available Aluminium-6061.

Table 3. Chemical composition of Al-6061.

\begin{tabular}{llllllllll}
\hline Component & Al & Mg & Si & Fe & Cu & Zn & Ti & Mn & Cr \\
\hline Amount & Rest & 0.84 & 0.62 & 0.23 & 0.22 & 0.1 & 0.1 & 0.03 & 0.22 \\
\hline
\end{tabular}

Table 4. Important properties of Al-6061.

\begin{tabular}{ll}
\hline Properties & Value \\
\hline Density: & $2.7 \mathrm{~g} / \mathrm{cm}^{3}$ \\
Modulus of Elasticity: $70-80 \mathrm{GPa}$ & $70-80 \mathrm{GPa}$ \\
Ultimate Tensile strength $(\mathrm{Mpa})$ & $110-152$ \\
BHN(500kg,10mm ball) & $30-33$ \\
Melting Point & $580^{\circ} \mathrm{c}$ \\
\hline
\end{tabular}

\subsection{Stir Casting Technique}

Chemicals used;

Exo-chloro ethane:

It is in tablet form. The exachloroethene is shown in figure 4 which is used to degas the material

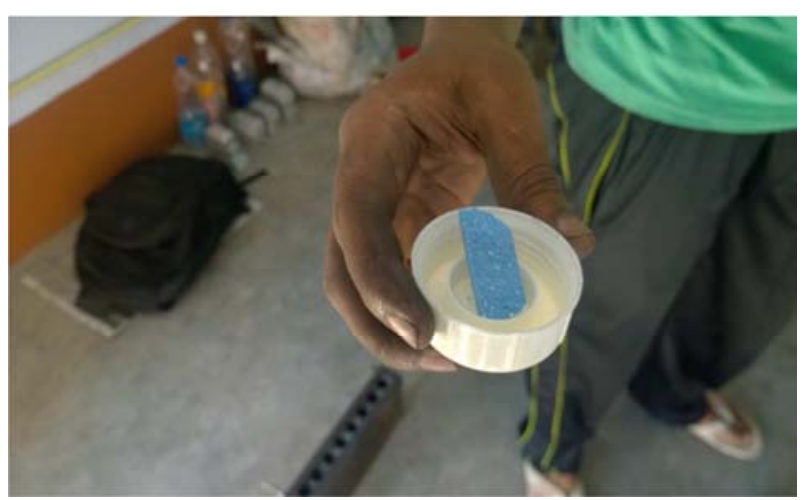

Figure 4. Exo-chloroethane.

\section{Coverall:}

It is in powder form which is shown in figure 5 which is used to remove the impurities and slag and also to increase oxidation resistance. Coverall is significantly used to increase the wettability

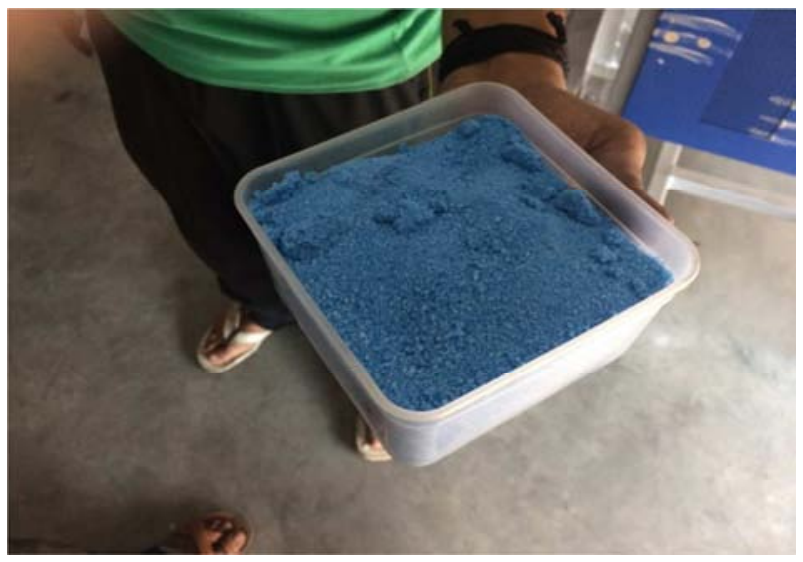

Figure 5. Coverall in powder form.

Magnesium chips:

It is in crystal form which is normally used to increase the wettability. If magnesium content increases more than $0.5 \%$ porosity will form, magnesium chips is as shown in figure 6

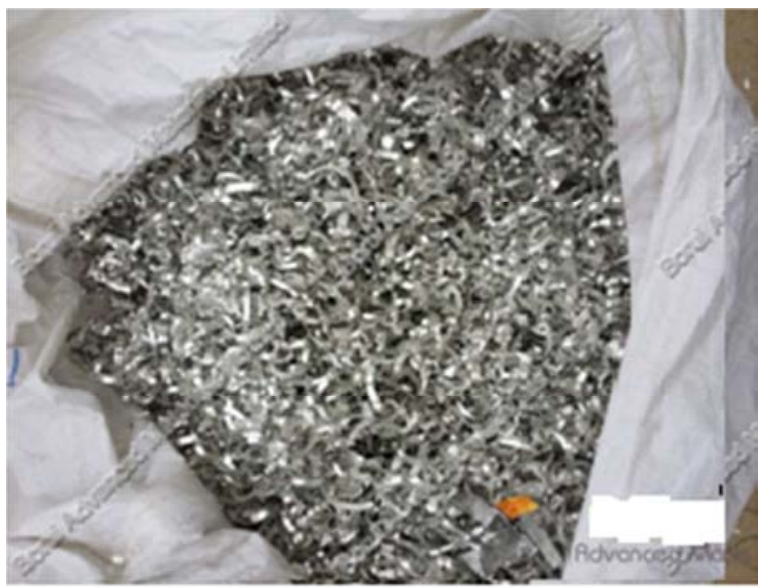

Figure 6. Magnesium chips.

\section{Components used:}

Die:

The die used (as shown in figure7) for the stir casting process is hallow cylinder. Where the diameter of the die is $25 \mathrm{~mm}$ and the length is $150 \mathrm{~mm}$

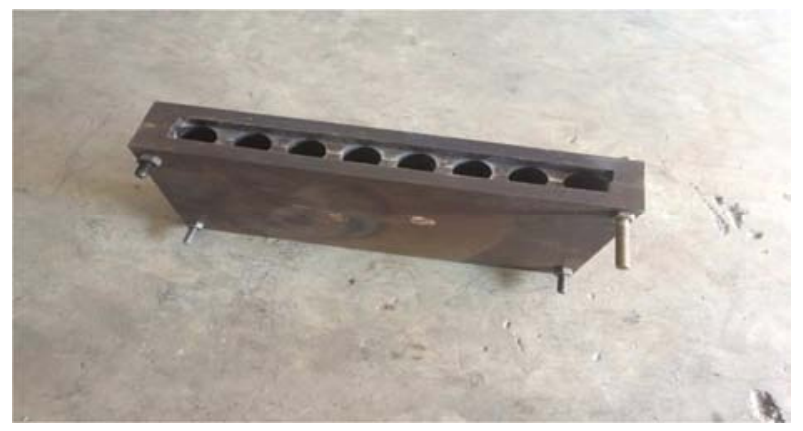

Figure 7. Die.

Crucible:

The thickness of the crucible (shown in figure8) used in the stir casting process is $15 \mathrm{~mm}$ 


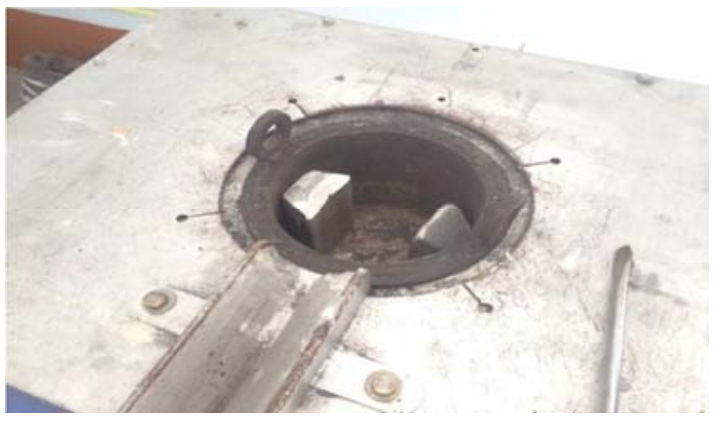

Figure 8. Crucible.

Furnace:

The material used for the furnace (as shown in figure9) is silicon carbide

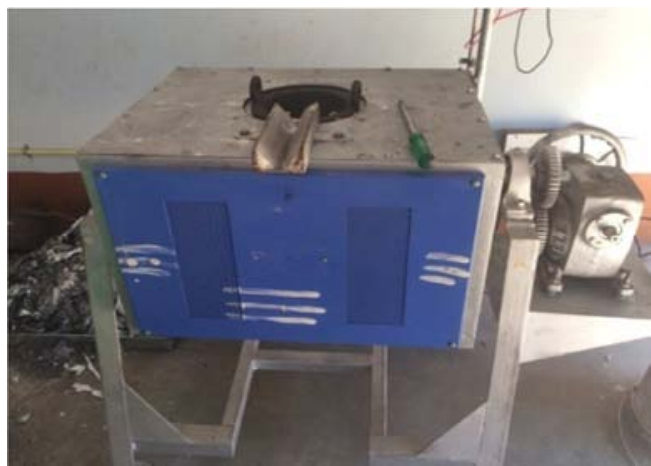

Figure 9. Furnace.

Pre-heater:

The pre-heater (figure10), the pre-heating temperature of the mould is $400-500$ deg Celsius. The material used for the mould is OHNS

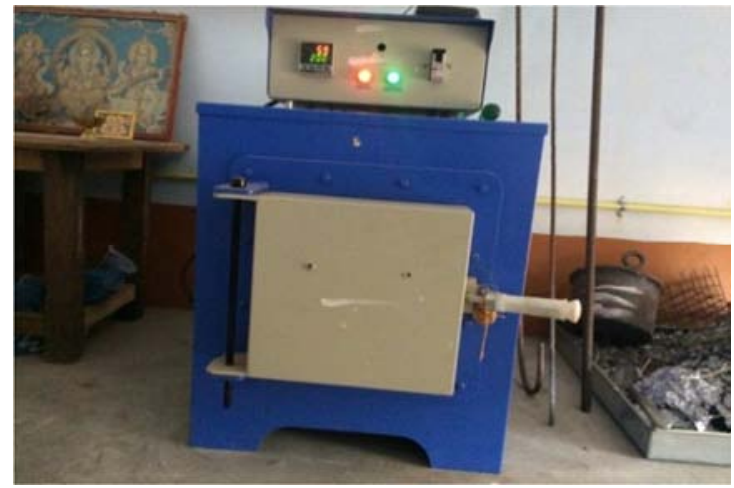

Figure 10. Pre-heater.

\section{Specimen preparation:}

Aluminum reinforced $\mathrm{MMC}$ is prepared by stir cast process. In this study, Al-6061 is used as matrix material with different $\%$ of red mud. Measured quantity of Al 6061 and red mud particles required to produce composites are $0 \%, 2 \%$, $4 \%, 6 \%$ and $8 \%$ by weight composition of aluminum the specimen preparation by pouring molten aluminum to suitable die arrangement followed by mixing of red mud particles and allowed the mixture to cool down to room temperature which is as shown in figure 11 . The process parameters were kept same for all the composition of MMC samples.

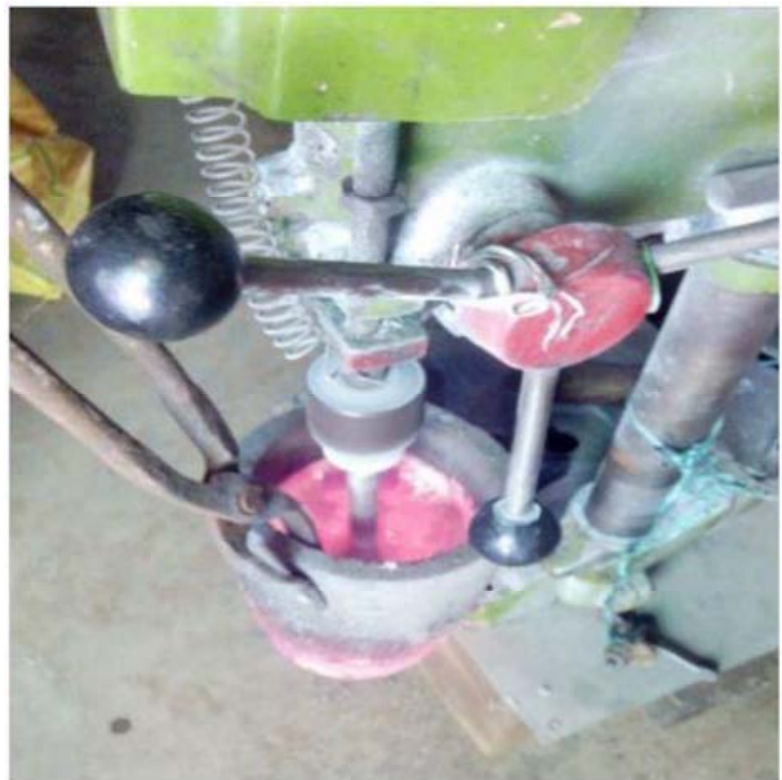

Figure 11. Stirring of red mud particles with molten Al6061.

Ceramic particles are heating up to preheating temperature for every sample. Then 1000 grams of aluminum 6061 is weighed for every sample and kept in the crucible until it melts. Later the chemicals like exachloroethane, Cover all, Magnesium chips are added to the composition because to degas the material and increase wet ability. After adding all chemicals, red mud is added to the aluminum and stirring the composition which allows the proper distribution of particles. After the mixture of aluminum and red mud is poured to die which is in liquid state and waited for $1 \mathrm{hr}$ to cool and then sample is removed from the die assembly and specimen is obtained.figure 12 depictsthe sample preparation setup where required composition of metal matrix composites are obtained.
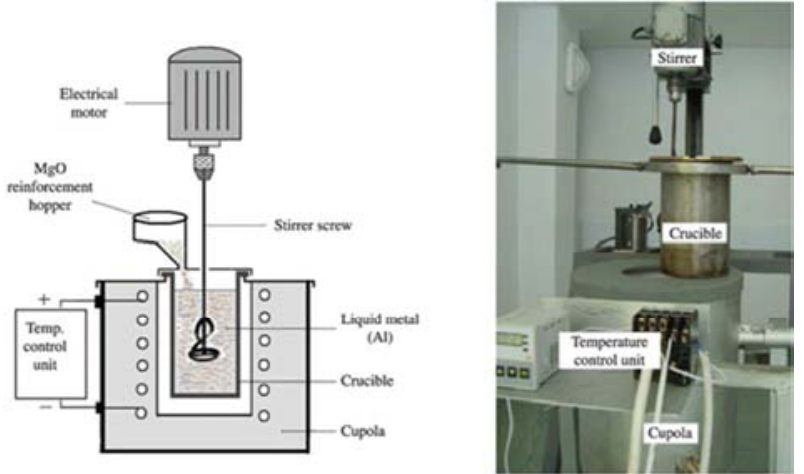

Figure 12. Specimen preparation.

\section{Experimentation}

Brinell hardness test;

To conduct hardness test brinell hardness equipment is used which is as shown in figure13. The Brinell scale 
characterizes the penetration of an indenter, loaded on material to asses hardness number. The typical test uses $3,000 \mathrm{kgf}(29.42 \mathrm{kN}$; 6,614harder materials, a tungsten carbide is substituted for the steel ball. The Brinell hardness test method consists of indenting the test material with a 10 $\mathrm{mm}$ diameter hardened steel or carbide ball subjected to a load. For softer materials the load can be reduced to excessive indentation. The full load is normally applied for 10 to 15 seconds for at least 30 seconds.

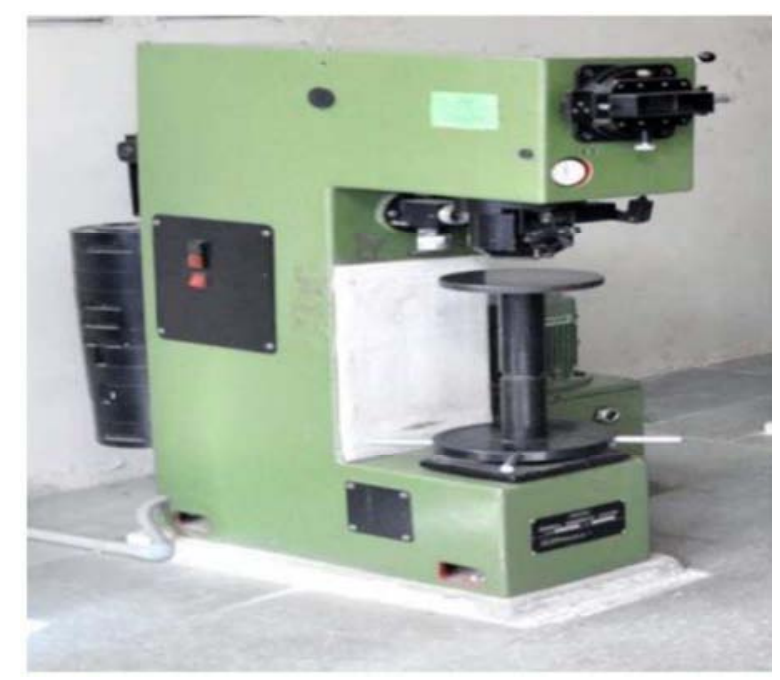

Figure 13. Hardness testing machine.

The diameter of the indentation left in the test material is measured with a low powered microscope. The brinell harness number is calculated by dividing the load applied $(500 \mathrm{~kg})$ by the surface area of the indentation

\section{Results}

Testing parameters;

Brinell hardness test results are compiled below,

The following test setup is arranged while conducting the tests

Steel Ball Diameter; $10 \mathrm{~mm}$

Load Applied; $500 \mathrm{~kg}$

Time of load application; $30 \mathrm{Sec}$.

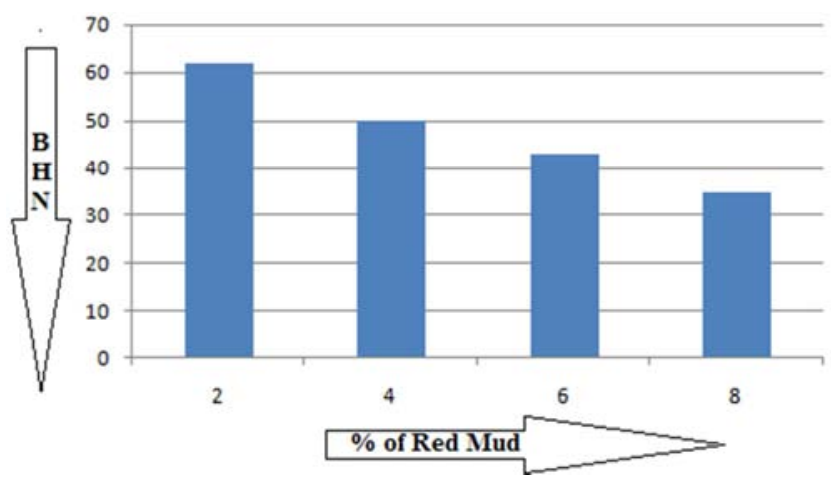

Figure 14. Hardness test results.

Based on obtained results it is clearly noted that the inclusion of the red mud is drastically affecting the hardness factor of the composite. The figure 13. Shows the variation of BHN with respect to the percentage composition of red mud. The material becomes more ductile by the increasing of the percentage composition of red mud. $8 \%$ red mud composite has a hardness of around $35.12 \mathrm{BHN}$ when compared to $2 \%$ red mud composite having brinell hardness number of 61.36 indicating a $43 \%$ decrease in hardness. The increase of the red mud composite weight percentage has decreased the hardness indicating the formability of the material.

\section{Conclusion}

Aluminium based metal matrix composites with iron oxide, silica and alumina inclusions with different weight percentage of $2 \%, 4 \%, 6 \%, 8 \%$ have been prepared successfully by adopting stir casting technique. Uniform distribution of red mud particles in aluminium matrix was achieved. Brinell hardness testing equipment is used to find out the hardness number of prepared samples which are allowed to experience the applied load to assess the resistance to indentation by the exterior of the material with response to internal composition. Different values for different samples are carefully recorded and plotted a graph which clearly depicts the effect of red mud on aluminium soft matrix. It was observed that the increase of the red mud particles has decreased thehardness number of samples indicating the formability of the material thereby failing to recover depth of harden abilityagainst applied load. It is concluded that sample filled with $2 \%$ of red mud particles exhibits excellent resistance to indentation which records $41 \%$ increase in hardness number as compared to the sample filled with $8 \%$ of red mud particles. The decreasing trend of hardness number was observed consecutively indicating the material softness upon increasing the percentage of inclusion of red mud particles which show case the inability of material to retain unreformeddue to overloading of red mud thereby reflecting the magnificent formability of materials.

\section{References}

[1] Karl Ulrich Kainer., "Basic of Metal Matrix Composites", Copyright (C) 2006 Wiley-VCH Verlag GmbH \& Co.

[2] Mr. Saravanan, C., Mr. Subramanian, K., Mr. Ananda K., V. And Mr. Sankara N., R. "Effect Of Particulate Reinforced Aluminium Metal Matrix Composite -A Review", Mechanics And Mechanical Engineering, Vol. 19, No. 1 (2015), pp 23.

[3] Mr. Shaikshavali G., Dr. VenugopalGoud E., Mr. Murali Mohan M. "Mechanical Properties Of A16061 Based Metal Matrix Composites Reinforced With Ceramic Particulates And Effect Of Age Hardening On Its Tensile Characteristics" International Journal Of Engineering Research And General Science Volume 4, Issue 2, (March- April, 2016).

[4] Mr. Jay P. Shirsat, Mr. A. K. Virkunwar., "Study Of Metal Matrix Composites of Automobile Brakes", International Journal On Recent And Innovation Trends in Computing And Communication, Volume: 4 Issue: 4., pp 100-104. 
[5] Lokesh KS et al, "Influence of Graphene on Hardness Number of Aluminium-7075 Based Metal Matrix Composites", Volume. 2 Issue. 12, December- 2017, International Journal of Innovative Science and Research Technology (IJISRT), www.ijisrt.com, ISSN - 2456-2165, PP:-285-289.

[6] Jithin Jose, P. Muthu., "Studies On Mechanical And Tribological Properties Of Aluminum Based Metal Matrix Composites - A Review", International Journal Of Advance Engineering And Research Development, Volume 2, Issue 11, Nov-2015.

[7] Dr. P. V. Krupakara, H. R. Ravikumar, "Corrosion Characterization Of Aluminium 6061 / Red Mud Metal Matrix Composites In Sea Water" International Journal Of Advanced Research In Chemical Science (IJARCS), Volume 2, Issue 6, June 2015, PP 52-55.
[8] P. V. Krupakara,"CorrosionCharacterization of A16061/Red MudMetalMatrix Composites" PortugaliaeElectrochimicaActa 2013, 31(3), 157-164.

[9] Neelima Devi Chinta, N. Selvaraj, V. Mahesh., "Characterization Of Aluminium-Red Mud Tungsten Carbide Hybrid Metal Matrix Composite", International Conference On Electrical, Electronics, And Optimization Techniques (ICEEOT)-2016.

[10] KS Lokesh, T Pinto, SM Ravi - Evaluation, 2017, Evaluation of Mechanical Properties and Wear Characterization of Polymer Composites under Varying Temperature Conditions: A Review, International Journal of Engineering and Information Systems (IJEAIS) ISSN: 2000-000X, Vol. 1 Issue 4, June- 2017, Pages: 64-68. 